\title{
Introduction of interactive learning into French university physics classrooms
}

\author{
Alexander Rudolph* \\ California State Polytechnic University, Pomona \\ E-mail: alrudolph@csupomona . edu
}

We report on a project to introduce interactive learning strategies (ILS) to physics classes at the Université Pierre et Marie Curie (UPMC), one of the leading science universities in France. In Spring 2012, instructors in two large introductory classes, first-year, second-semester mechanics, and second-year introductory E\&M, enrolling approximately 500 and 250 students respectively, introduced ILS into some, but not all of the sections of each class. Pre- and post-instruction assessments (FCI and CSEM respectively) were given, along with a series of demographics questions. Since not all lecture or recitation sections in these classes used ILS, we were able to compare the results of the FCI and CSEM between interactive and non-interactive classes taught simultaneously with the same curriculum. We also analyzed final exam results, as well as the results of student and instructor attitude surveys between classes.

Our results show that ILS are effective at improving student learning by all measures used: research-validated concept inventories and final exam scores, on both conceptual and traditional problem-solving questions. Multiple Linear Regression analysis reveals that interactivity in the classroom is a significant predictor of student learning, showing a similar or stronger relationship with student learning than such ascribed characteristics as parents' education, and achieved characteristics such as GPA and hours studied per week. Analysis of student and instructors attitudes shows that both groups believe that ILS improve student learning in the physics classroom, and increases student engagement and motivation. All of the instructors who used ILS in this study plan to continue its use.

This work is based on our paper which was published recently in Physical Review Special Topics - Physics Education Research; it was an editor's suggestion when it came out: http://journals.aps.org/prstper/issues/10/1

Frontiers of Fundamental Physics 14 - FFP14,

15-18 July 2014

Aix Marseille University (AMU) Saint-Charles Campus, Marseille

\footnotetext{
* Speaker.
} 